\title{
Racial, Ethnic, and Income-Based Disparities in Health Care-Related Trust
}

J Gen Intern Med 36(4): 1126-8

DOI: $10.1007 /$ s1 1606-020-06568-6

(c) Society of General Internal Medicine 2021
P atients who trust their physician and the health care system are more likely to receive preventive care, have better self-rated health, and report greater satisfaction than those with lower trust. ${ }^{1-3}$ Researchers have posited that racial and ethnic differences in trust may be a factor causing disparities in health outcomes, since Black Americans have long reported lower trust than whites. ${ }^{2,4,5} \mathrm{We}$ use a large, national sample to explore racial/ethnic and income-based disparities in health care-related trust, as the latter have received less attention. ${ }^{2,4}$, 5

\section{METHODS}

We used data from the September 2018 Health Reform Monitoring Survey ( $n=4946)$, which uses Ipsos' KnowledgePanel, a nationally representative internet panel of English and Spanish speakers aged 18-64. ${ }^{6}$ To reach low-income respondents, Ipsos provides access to the internet and computers when needed.

Participants were asked how much they agreed or disagreed on a 5-point scale to statements affirming trust in four levels of the health care system: my personal doctor or health care provider (personal doctor), most doctors, most hospitals, the overall health care system. Trust in one's personal doctor was only asked of those reporting a personal doctor.

We examined relationships between race/ethnicity (white (non-Latino), Black (non-Latino), Latino, and other), family income ( $\leq 138 \%$ FPL, 139-249\% FPL, 250-399\% FPL, and $400 \%+$ FPL), and each trust variable, controlling for gender, age, health status, and having a disability. We estimated multinomial logistic regression models since the trust variables had multiple categories. We combined strongly and somewhat disagree because of limited responses, and for trust in one's

An earlier version of this paper was presented at the June 2019 Academy Health Annual Research Meeting.

Received December 20, 2019

Accepted December 22, 2020

Published online January 25, 2021 personal doctor, we combined neutral and disagree responses. Logistic regression was used to examine characteristics related to having a personal doctor. Analyses were weighted to be nationally representative and adjust for the sample's complex design. Bivariate findings (available from authors) were consistent with multivariate results.

\section{RESULTS}

Trust was much higher for one's personal doctor than for other levels of the health care system. Of the $63.2 \%$ of respondents who had a personal doctor, almost two-thirds (64.6\%) strongly trusted (i.e., strongly agreed) their personal doctor (not shown). Less than half as many participants (24.2\%) strongly trusted most doctors, and even fewer reported strongly trusting most hospitals or the health care system (19.9\% and $16.0 \%$, respectively).

Among those with a personal doctor, Blacks and Latinos did not differ significantly in their level of trust in their doctor compared with whites (Table 1). Latinos, though, were less likely to have a personal doctor than were whites $(\mathrm{OR}=.64)$. Those in the three lower income groups, however, were at least twice as likely not to trust (i.e., neutral or disagreed) their personal doctor as those in the highest income group (400\%+ FPL). Additionally, respondents in the lowest two income groups had approximately half the odds of having a personal doctor compared to the highest income group.

There were also income-based differences in trust in most doctors and most hospitals (Table 2). Those in the three lower income groups were $81-106 \%$ more likely to report not trusting (i.e., disagreed) most doctors compared to the highest income group. Similarly, those with lower incomes were substantially more likely $(45-71 \%)$ to report not trusting most hospitals than were the highest income group. There were, in contrast, no significant differences in trust in most doctors or trust in most hospitals by race/ethnicity.

Income was not consistently related to trust in the health care system. While race/ethnicity was related, Blacks and Latinos were less likely to report not trusting the health care system than whites $(\mathrm{RRR}=.37$ and $\mathrm{RRR}=.58$, respectively).

\section{DISCUSSION}

Using a large, national survey, we found Blacks and Latinos did not significantly differ in their level of trust 
Table 1 Key Regression Model Results for Having a Personal Doctor or Health Care Provider, and Trusting that Provider

\begin{tabular}{|c|c|c|c|}
\hline & $\begin{array}{l}\text { Having a personal doctor/health } \\
\text { care provider } \\
\text { Odds ratios }(95 \% \mathrm{CI})\end{array}$ & \multicolumn{2}{|c|}{ Trust in personal doctor/health care provider } \\
\hline \multicolumn{4}{|l|}{ Race/ethnicity } \\
\hline White $(n=3416)$ & $(1.00)$ & $(1.00)$ & $(1.00)$ \\
\hline \multicolumn{4}{|l|}{ Family income } \\
\hline$<138 \%$ FPL $(n=909)$ & $0.56(0.45,0.69)$ & $0.97(0.71-1.32)$ & $3.12(1.78-5.47)$ \\
\hline $139-249 \%$ FPL $(n=845)$ & $0.55(0.43,0.70)$ & $1.17(0.91-1.51)$ & $2.05(1.38-3.05)$ \\
\hline $250-399 \%$ FPL $(n=946)$ & $0.84(0.66,1.07)$ & $1.14(0.92-1.41)$ & $2.55(1.44-4.50)$ \\
\hline $400 \%+$ FPL $(n=2246)$ & $(1.00)$ & $(1.00)$ & $(1.00)$ \\
\hline
\end{tabular}

Logistic regression was used to examine characteristics of respondents who had a personal doctor. Multinomial logistic regression was used with the $63.2 \%(n=3419)$ respondents with a personal doctor to compare characteristics between three groups: those who strongly agreed, somewhat agreed, and were neutral or disagreed to the statement "I trust my doctor." All models controlled for gender, age, health status, and having a disability and were weighted to be nationally representative and adjusted for the sample's complex design

Bold indicates an odds ratio or relative risk ratio statistically significant at the $p<.05$ level.

for their personal doctor, most doctors, or most hospitals compared to whites, and were actually slightly more trusting of the overall health care system than whites. However, lower income respondents had less trust in their personal doctor, most doctors, and most hospitals than did higher income respondents. Future research is needed to confirm these findings and to explore racial/ethnic differences within income groups.

Table 2 Racial/Ethnic and Income-Based Differences in Trust in Most Doctors, Most Hospitals, and the Health Care System

\begin{tabular}{|c|c|c|c|}
\hline & \multicolumn{3}{|c|}{ Relative risk ratios compared to strongly agree } \\
\hline & $\begin{array}{l}\text { Somewhat agree } \\
\text { RRR (95\% CI) }\end{array}$ & $\begin{array}{l}\text { Neutral } \\
\text { RRR (95\% CI) }\end{array}$ & $\begin{array}{l}\text { Disagree } \\
\text { RRR (95\% CI) }\end{array}$ \\
\hline \multicolumn{4}{|l|}{ Trust in most doctors } \\
\hline \multicolumn{4}{|l|}{ Race/ethnicity } \\
\hline White $(n=3416)$ & $(1.00)$ & $(1.00)$ & $(1.00)$ \\
\hline African American $(n=457)$ & $0.83(0.57-1.19)$ & $1.16(0.81-1.65)$ & $0.80(0.57-1.13)$ \\
\hline Latino $(n=726)$ & $0.89(0.73-1.08)$ & $0.81(0.57-1.14)$ & $0.76(0.47-1.25)$ \\
\hline Other $(n=344)$ & $0.87(0.64-1.18)$ & $0.94(0.65-1.36)$ & $0.91(0.47-1.75)$ \\
\hline \multicolumn{4}{|l|}{ Family income } \\
\hline$\leq 138 \%$ FPL $(n=909)$ & $0.73(0.56-0.94)$ & $1.38(1.04-1.82)$ & $1.84(1.22-2.77)$ \\
\hline $139-249 \%$ FPL $(n=845)$ & $1.01(0.77-1.32)$ & $1.34(1.00-1.79)$ & $2.06(1.43-2.97)$ \\
\hline $250-399 \%$ FPL $(n=946)$ & $1.04(0.87-1.24)$ & $1.22(0.99-1.51)$ & $1.81(1.32-2.47)$ \\
\hline $400 \%+\operatorname{FPL}(n=2246)$ & $(1.00)$ & $(1.00)$ & $(1.00)$ \\
\hline \multicolumn{4}{|l|}{ Trust in most hospitals } \\
\hline \multicolumn{4}{|l|}{ Race/ethnicity } \\
\hline White $(n=3416)$ & $(1.00)$ & $(1.00)$ & $(1.00)$ \\
\hline African American $(n=457)$ & $0.74(0.53-1.04)$ & $1.12(0.75-1.65)$ & $0.70(0.46-1.05)$ \\
\hline Latino $(n=726)$ & $0.95(0.77-1.17)$ & $0.98(0.72-1.34)$ & $0.89(0.64-1.22)$ \\
\hline Other $(n=344)$ & $0.89(0.66-1.21)$ & $0.92(0.62-1.35)$ & $0.77(0.40-1.48)$ \\
\hline \multicolumn{4}{|l|}{ Family income } \\
\hline$\leq 138 \%$ FPL $(n=909)$ & $0.86(0.68-1.08)$ & $1.27(0.98-1.66)$ & $1.71(1.28-2.30)$ \\
\hline $139-249 \%$ FPL $(n=845)$ & $1.10(0.84-1.46)$ & $1.19(0.89-1.61)$ & $1.67(1.16-2.39)$ \\
\hline $250-399 \%$ FPL $(n=946)$ & $1.08(0.85-1.38)$ & $1.11(0.88-1.41)$ & $1.45(1.05-2.00)$ \\
\hline $400 \%+$ FPL $(n=2246)$ & $(1.00)$ & $(1.00)$ & $(1.00)$ \\
\hline \multicolumn{4}{|l|}{ Trust in the health care system } \\
\hline \multicolumn{4}{|l|}{ Race/ethnicity } \\
\hline White $(n=3416)$ & $(1.00)$ & $(1.00)$ & $(1.00)$ \\
\hline African American $(n=457)$ & $0.70(0.48-1.01)$ & $0.83(0.57-1.22)$ & $0.37(0.24-0.56)$ \\
\hline Latino $(n=726)$ & $0.81(0.65-1.01)$ & $0.72(0.58-0.89)$ & $0.58(0.38-0.90)$ \\
\hline Other $(n=344)$ & $1.02(0.68-1.54)$ & $1.05(0.66-1.65)$ & $0.78(0.42-1.47)$ \\
\hline \multicolumn{4}{|l|}{ Family income } \\
\hline$\leq 138 \%$ FPL $(n=909)$ & $0.68(0.52-0.89)$ & $0.97(0.76-1.24)$ & $1.01(0.75-1.36)$ \\
\hline $139-249 \%$ FPL $(n=845)$ & $0.84(0.62-1.14)$ & $1.23(0.92-1.64)$ & $1.29(0.90-1.84)$ \\
\hline $250-399 \%$ FPL $(n=946)$ & $0.89(0.66-1.20)$ & $1.16(0.85-1.59)$ & $1.20(0.89-1.63)$ \\
\hline $400 \%+$ FPL $(n=2246)$ & $(1.00)$ & $(1.00)$ & $(1.00)$ \\
\hline
\end{tabular}

Multinomial logistic regression was used to compare characteristics between four groups: those who strongly agreed, somewhat agreed, neither agreed nor disagreed, and disagreed to the statement "I trust most doctors [most hospitals/the health care system]." All models controlled for gender, age, health status, and having a disability and were weighted to be nationally representative and adjusted for the sample's complex design Bold indicates a relative risk ratio statistically significant at the $p<.05$ level 
This study's findings underscore the importance of monitoring levels of health care-related trust, and highlight the need for health care providers and organizations to build trust with all patients, particularly those with lower incomes, which disproportionately includes minority populations.

Jessica Greene, Ph.D. ${ }^{1}$

Sharon K. Long, Ph.D. ${ }^{2}$

${ }^{1}$ Marxe School of Public and International Affairs,

Baruch College, City University of New York,

New York, NY, USA

${ }^{2}$ The Urban Institute, Washington, DC, USA

Corresponding Author: Jessica Greene, Ph.D.; Marxe School of Public and International Affairs, Baruch College, City University of New York, New York, NY, USA (e-mail: Jessica.greene@baruch.cuny.edu).

Funding The Robert Wood Johnson Foundation funds the Health Reform Monitoring Survey.

\section{Compliance with Ethical Standards:}

Conflict of Interest: The authors declare that they do not have a conflict of interest.

\section{REFERENCES}

1. Mollborn S, Stepanikova I, Cook KS. Delayed Care and Unmet Needs among Health Care System Users: When Does Fiduciary Trust in a Physician Matter? Health Serv Res. 2005;40(6p1):1898-917.

2. Doescher MP, Saver BG, Franks P, Fiscella K. Racial and ethnic disparities in perceptions of physician style and trust. Arch Fam Med. 2000;9(10):1156-63.

3. Musa D, Schulz R, Harris R, Silverman M, Thomas SB. Trust in the health care system and the use of preventive health services by older black and white adults. Am J Public Health. 2009;99(7):1293-9.

4. Birkhäuer J, Gaab J, Kossowsky J, Hasler S, Krummenacher P, Werner C, et al. Trust in the health care professional and health outcome: A metaanalysis. PLoS One. 2017;12(2):e0170988.

5. Martin KD, Roter DL, Beach MC, Carson KA, Cooper LA. Physician communication behaviors and trust among black and white patients with hypertension. Med Care. 2013;51(2):151-7.

6. Long S, Keeney G, Zuckerman S, Goin DE, Wissoker D, Blavin F, Blumberg LJ, Clemans-Cope L, Holahan J, Hempstead K. The Health Reform Monitoring Survey: Addressing data gaps to provide timely insights into The Affordable Care Act. Health Aff. 2014;33(1): 161-167.

Publisher's Note: Springer Nature remains neutral with regard to jurisdictional claims in published maps and institutional affiliations. 